\title{
Automatic Measurement of Drilling Parameters to Evaluate the Mechanical Properties of Soils
}

\author{
${ }^{1,2}$ Marilena Cardu, ${ }^{1,2}$ Pierpaolo Oreste, ${ }^{3}$ Daniele Pettinau and ${ }^{4}$ Davide Guidarelli \\ ${ }^{1}$ Department of Environment, Land and Infrastructures (DIATI), \\ Faculty of Engineering, Politecnico di Torino, 24 Corso Duca degli Abruzzi, 10129, Turin, Italy \\ ${ }^{2}$ CNR-IGAG (National Research Council), Turin, Italy \\ ${ }^{3}$ ANAS (Italian Road Society), Turin, Italy \\ ${ }^{4}$ Department of Engineer, Alessandria, Italy
}

Received 2012-06-25, Revised 2012-09-26; Accepted 2013-07-01

\begin{abstract}
Any underground work, carried out either to perform excavations, should be based on detailed knowledge of the geological, hydrogeological and geomechanical conditions of the underlying materials. The continuous automatic diagraphy is a test that consists in the continuous surveying of drilling parameters, with total destruction of the core, which can be used, together with geognostic probing surveys and a detailed definition of the stratigraphy of the subsoil, to evaluate the geotechnical characteristics of soils. One of the main advantages of the use of instrumented surveys is that of being able to perform a greater number of in situ tests at the same costs and times. Over the last two decades years, the use of rotating hydraulic surveys for geognostic investigations, combined with automatic acquisition systems of the main drilling parameters, have become widespread. The study presents the results obtained during an investigation campaign of the subsoil of areas in Piedmont, Italy, which was necessary to carry out important civil engineering works.
\end{abstract}

Keywords: Soil Characterization, DAC Tests, Drilling Parameters, Survey, Specific Excavation Energy, Continuous Automatic Diagraphy

\section{INTRODUCTION}

One of the indirect methods used to evaluate the geotechnical conditions and stress state of the subsoil (Cardu et al., 2009; Cardu and Oreste, 2011; De Rienzo et al., 2008; 2009; De Rienzo and Oreste, 2011; Oggeri and Oreste, 2012; Oreste, 2005) involves the monitoring of drilling parameters through instrumented surveys, generally with destruction of the core. This practice is very flexible and versatile, efficacious and quick in any geological context and it makes it possible to obtain continuous information on the soil or rock not only through analysis of the drilling debris (which can only characterise the ground through chemical-physical and particle size distribution tests), but also through the evaluation of the resistance of the ground or rock to the drilling. The evaluation of the soil characteristics through this technique can also be useful to plan the recycling of the muck for engineering purposes (Bellopede et al., 2011).

Both rotating hydraulic surveys and automatic acquisition systems of the main drilling parameters have been extensively affirmed in Europe (the continuous automatic diagraphy of the drilling parameters has been compulsory in Scandinavia since the seventies), allowing some characteristic magnitudes to be continuously recorded. This process will be dealt with hereafter. This instrument is normally used to evaluate drilling with destruction of the core or, but more rarely, continuous probe drilling.

Numerous factors, which are not yet fully understood, are involved in rotation drilling; the progression speed of the tool is linked to the parameters directly imposed by the operator to obtain the best yield and to others that are due to the response of the drilling system.

Corresponding Author: Marilena Cardu, Department of Environment, Land and Infrastructures (DIATI), Faculty of Engineering, Politecnico di Torino, 24 Corso Duca degli Abruzzi, 10129, Turin, Italy 


\section{MATERIALS AND METHODS}

\subsection{Continuous Automatic Diagraphy (DAC)}

The following parameters are generally varied during the perforation: the force and the rotation speed of the tool, the pressure of the drilling liquid and the type and diameter of the drilling tool. Drillings with destruction of the core are carried out for many reasons: as an alternative to probing (in well known stratigraphic areas), for the realization of deep foundations, to place instrumentation or for water research purposes.

The analysis and interpretation of the acquired data are often influenced by the diversity of the instruments and drilling methods that are used.

The parameters that are usually monitored during drilling are:

- The progression speed

- Applied torque on the tool

- $\quad$ Pressure of the drilling fluid

- Type and diameter of the tool

- Drilling method

- Rotation speed of the rod

- Thrust at the rod

Through an evaluation of the drilling parameters and an examination of the drilling debris, it is possible to understand whether the anomalies encountered in the drilling parameters can be ascribed to variations of a geological nature or of the stress state of the ground.

This aspect is particularly important when it is necessary to evaluate the behavior of the ground below foundations and in particular for bridge pile foundations.

In this case, typical in situ geotechnical tests would not be able to evaluate this de-stressing, which is the first important sign of foundation undermining. Instrumented surveys, instead, can easily define the entity of the phenomenon through an examination of the drilling parameters with the depth, together with an analysis of the drilling debris. The application of instrumented surveys to evaluate the efficacy of a ground consolidation is also important, both concerning the consistency of the treated material and for the evaluation of its extension.

The data obtained from the recording of the drilling parameters are generally compared on an empirical basis with stratigraphic surveys in order to have information on the consistency of the ground.

The specific drilling energy is the quantity of work necessary to drill a unit volume of ground and it can allow the ground stratification to be known. In this way it is therefore possible to obtain the energetic differentiation of the crossed layers, but it is not possible to supply information on the geotechnical characteristics of the ground.

The specific energy Es can be calculated, for rotating drilling tools, using the following relation (Teale, 1965) Equation 1:

$$
E=\frac{(F \cdot v+C \cdot \omega) \cdot \frac{s}{v}}{A \cdot s}=\frac{F}{A}+\frac{C \cdot \omega}{A \cdot v}
$$

Where:

$\mathrm{F}=\mathrm{The}$ axial thrust force applied to the tool, in $\mathrm{kN}$ Equation 2:

$\mathrm{F}=\mathrm{p} \cdot 1+\mathrm{P}+\mathrm{S}_{0}$

$\mathrm{p}=$ The linear weight of the drilling rod, in $\mathrm{kN} / \mathrm{m}$

$1=$ The length of the drill stem, in $\mathrm{m}$

$\mathrm{P}=$ The weight of the excavation tool and of the rotating head, in $\mathrm{kN}$

$\mathrm{S}_{0}=$ The thrust produced by the hydraulic piston on the drill stem head, in $\mathrm{kN}$

$\mathrm{A}=$ The cross section of the borehole, in $\mathrm{m}^{2}$;

$\mathrm{C}=$ Torque applied to the excavation tool, in $\mathrm{kNm}$ (placed equal to that produced on the drill stem head);

$\omega=$ Rotation speed, in $\mathrm{rad} / \mathrm{sec}$

$\mathrm{v}=$ Tool progression speed, in $\mathrm{m} / \mathrm{sec}$

The specific energy allows the effects on the drilling, caused by changes in the thrust and rotation speed of the drill system, to be considered and it is a parameter which is only a function of the excavated ground, the employed tool being equal. It is advisable to keep the thrust and rotation speed of the tool constant when drilling a borehole, in order to be able to interpret the results more accurately. The importance of the stress state of the medium on the drilling resistance is shown by the increase in the specific energy with depth, the ground being equal: Increases that vary from 1 to $7 \mathrm{MJ} / \mathrm{m}^{3}$ are usually obtained per metre of depth (the lower limit for silty sand and the higher for gravel).

The results of investigations conducted in some sites in Piedmont, Italy are reported hereafter.

\subsection{The Turin Subsoil: Geological and Geotechnical Characterisation}

The numerous hydrogeological and geotechnical investigations that have been carried out in the Turin area over the years have made it possible to realise about 400 stratigraphs, thanks to which a tridimensional model has been reconstructed over an area of $70 \mathrm{~km}^{2}$ which includes the urban territory, to an investigation depth of about $60 \mathrm{~m}$ (De Rienzo et al., 2008; 2009; De Rienzo and Oreste, 2011). 
From these studies, it has emerged that the Turin city subsoil is prevalently made up of an alluvial gravellysandy horizon (Quaternary) of a thickness that varies between 30 and $50 \mathrm{~m}$, passing from the morth-western sector to the south-eastern one. These deposits are bounded on the bottom by a clay succession.

The alluvial sediment cover shows an accentuated variety of mechanical characteristics due to the presence of levels and/or lenses of cemented material. The cementation is vertically distributed heterogeneously with poor lateral continuity.

The knowledge of the geotechnical parameters of the ground is of fundamental importance for the correct design of the underground structures and of the excavation machines. Furthermore, the detailed knowledge of the characteristics of the soil allows its rational management for reuse as a building material.

The work conducted to excavate the underground system, which is at present still underway in the city of Turin, has made it possible to carry out sampling along the line, which is characterised by soils with different classes of cementation. The different geognostic investigations (Barla and Vai, 1999) have concerned various in situ test campaigns: geognostic rotation surveys (with continuous probing), geognostic surveys with destruction of the core, Dynamic Penetrometric Tests (NSPT), PA.PE.RO (PArametri di PErforazione ROdio-Rodio Drilling Parameters) type instrumented drilling tests and DAC-Tests, geophysical type measurements, Lefranc permeability tests, plate-load tests in shafts and laboratory tests, including: grain size distribution analyses on samples and mechanical tests on cemented soil samples. These investigation campaigns had the purpose of characterising the soils along the route of the underground system from the geological, lithostratigraphic and geotechnical points of view and of producing a hydrogeological model in order to identify any interferences between the construction works and the water table. The correlations established at the points in which the diagraphies and the surveys were carried out next to each other were extrapolated from the interpretation of the data derived from the drillings (diagraphies of the drilling parameters) in the areas that were not reached by the continuous probing surveys.

The specific energy values obtained from the diagraphies were treated, by eliminating the peak values and then mediated along $10 \mathrm{~cm}$ intervals of depth. The mean specific energy values were then calculated (Barla and Vai, 1999).
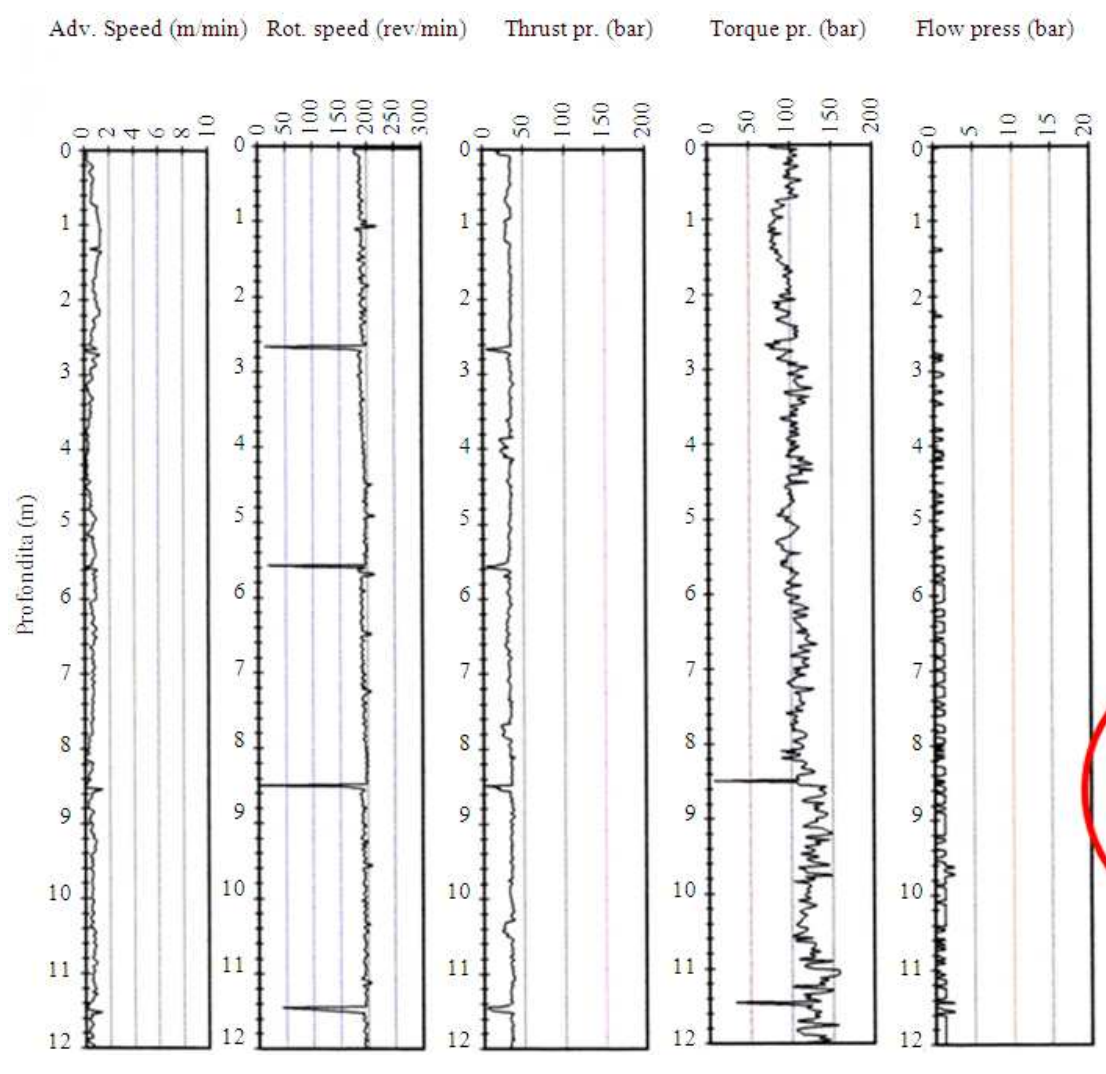

Spec energy (k,1m3) Thrust pr. P1 (bar)

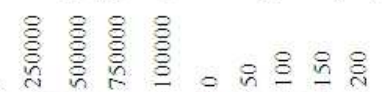


Marilena Cardu et al. / American Journal of Applied Sciences 10 (7): 654-663, 2013
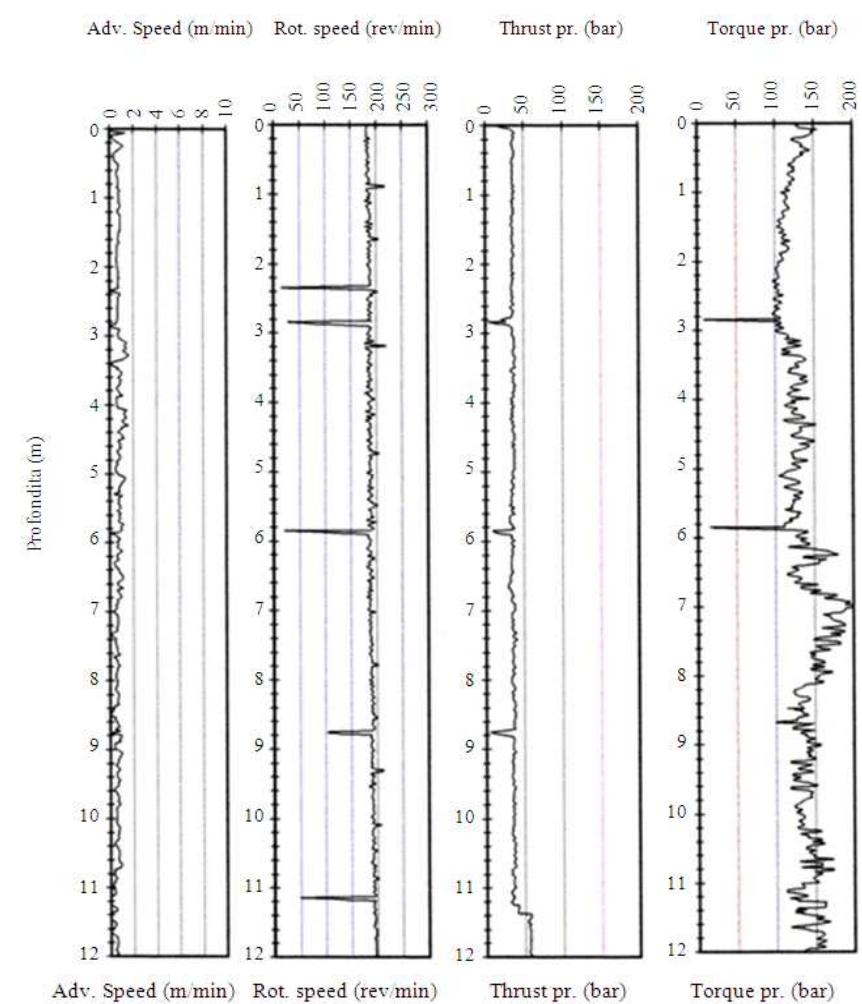

Flow press (bar)

Spec energy $(\mathrm{k}, 1 \mathrm{~m} 3)$ Thrust pr. P1 (bar)

$\S \S \S 8$
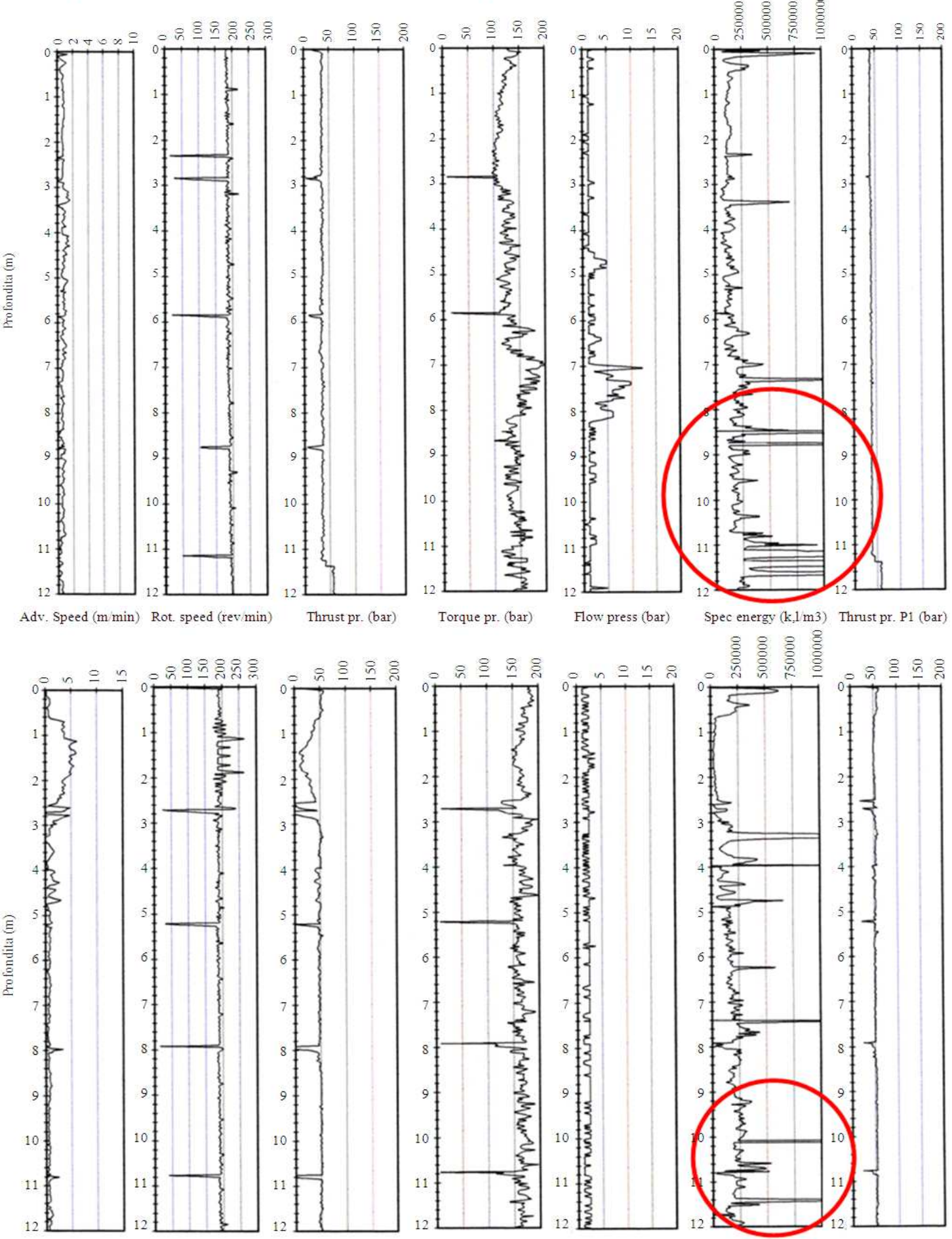

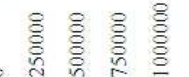

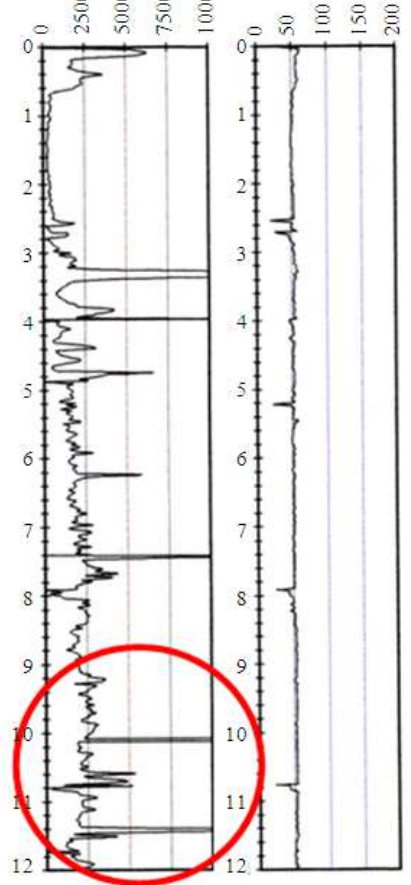

Fig. 1. Diagraphies D1-D3 of the drilling parameters recently realized in the subsoil of Turin: red circles indicate the increase of the specific energy due to cemented layers 


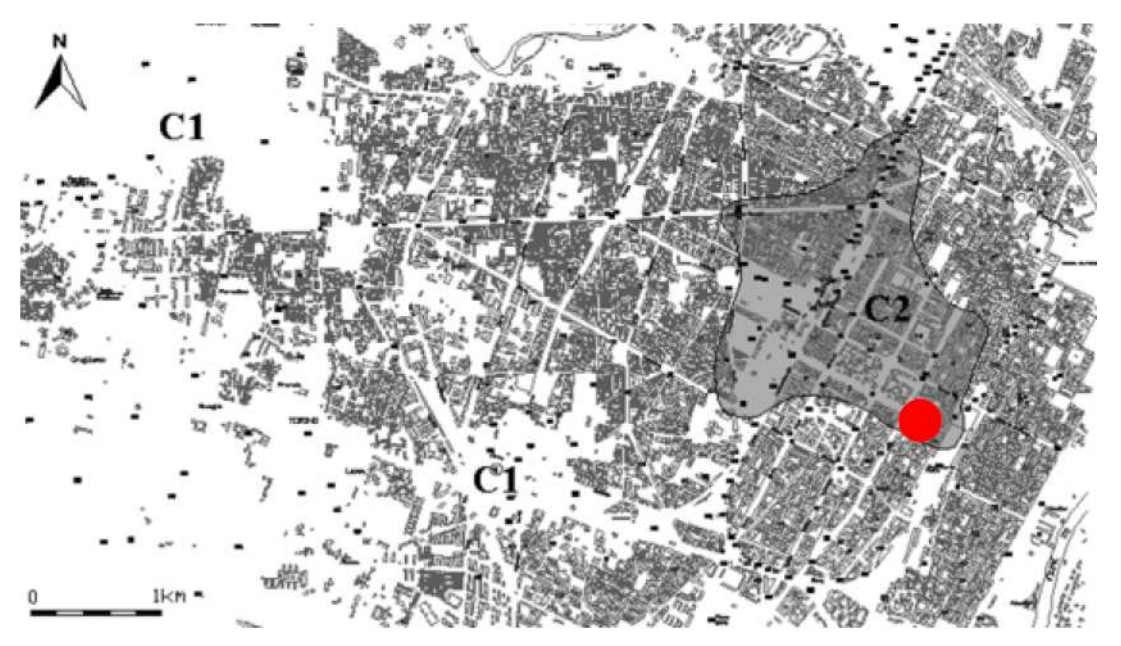

Fig. 2. Map of the cementation degree in the subsoil of Turin (10 m below the surface) (from De Rienzo and Oreste, 2011): C1: not cemented layers; C2: cemented layers; red circle: location of the realized diagraphies, on the border of the area $\mathrm{C} 2$

Laboratory studies have shown that the ground is cemented, when there is a disparity in the specific energy values $E$ of (Barla and Vai, 1999) Equation 3:

$$
\mathrm{E}\left(\mathrm{MJ} / \mathrm{m}^{3}\right) \geq 125+4 \cdot \mathrm{z} ; \mathrm{s} \geq 40 \mathrm{~cm}
$$

where, $\mathrm{z}(\mathrm{m})$ is the depth respect to the ground level and $\mathrm{s}(\mathrm{cm})$ is the thickness of the ground layer.

Specific energy values of $E \geq 142 \mathrm{MJ} / \mathrm{m}^{3}$ with $\mathrm{s} \geq 40 \mathrm{~cm}$ make it impossible to excavate diaphragms with a clamshell bucket shovel (Barla and Vai, 1999). Some diagraphies realized more recently have allowed to validate the developed 3D geotechnical model of the subsoil of Turin (De Rienzo et al., 2008; De Rienzo and Oreste, 2011), identifying cemented layers (with values of specific energy higher than those related to not cemented levels) to a depth of about $10 \mathrm{~m}$ from the surface (Fig. 1 and 2).

\section{RESULTS}

\subsection{Case Studies of Investigations to Evaluate the Foundations of Bridges}

The Italian Agency ANAS, Italian Piedmont Roads Department, carried out some years ago a continuous geognostic investigation campaign to monitor the drilling parameters in the foundation soils of some of the most important national road bridges across the rivers in Piedmont.

The main parameters that were monitored were: the oil pressure in the feed roll of the drill stem, drilling fluid pressure, oil pressure in the hydraulic engine of the drill stem and rotation speed of the drill rods.
The trend of the specific energy with depth was evaluated on the basis of these parameters in order to calculate the conditions of the ground in the subsoil and, in particular, its compactness below the foundations. Case studies on bridges over the Gesso Stream in Cuneo and over River Po in Pieve Po are dealt with hereafter.

\section{DISCUSSION}

\subsection{Bridge over the Gesso Stream, Cuneo, Italy}

The investigations on National Road 22 in Cuneo concerned the bridge over the Gesso Stream.

Three diagraphies were conducted, for a maximum depth of $10 \mathrm{~m}$, close to the abutment on the Cuneo side (Fig. 3) by the Geotecno Company. Adjacent to the calibration diagraphy shown in Fig. 4, a core drilling was carried out (Fig. 5).

From the diagraphy shown in Fig. 6 (upper side), it can be observed that the specific drilling energy is high to a depth of about $5 \mathrm{~m}$ and then diminishes progressively till it reaches values of the order of $80-100 \mathrm{MJ} / \mathrm{m}^{3}$.

This reduction is basically due to an increase in the advancement speed, as the thrust of the tool, the injection pressure, the rotation torque and the velocity are almost constant.

In the diagraphy shown in Fig. 7, two sharp reductions in the specific energy can be seen, at 4.5 and $5.5 \mathrm{~m}$, respectively.

In the first case, specific energyis reduced to values of $80-100 \mathrm{MJ} / \mathrm{m}^{3}$, while in the second case it even reaches values of almost nil. 
Marilena Cardu et al. / American Journal of Applied Sciences 10 (7): 654-663, 2013

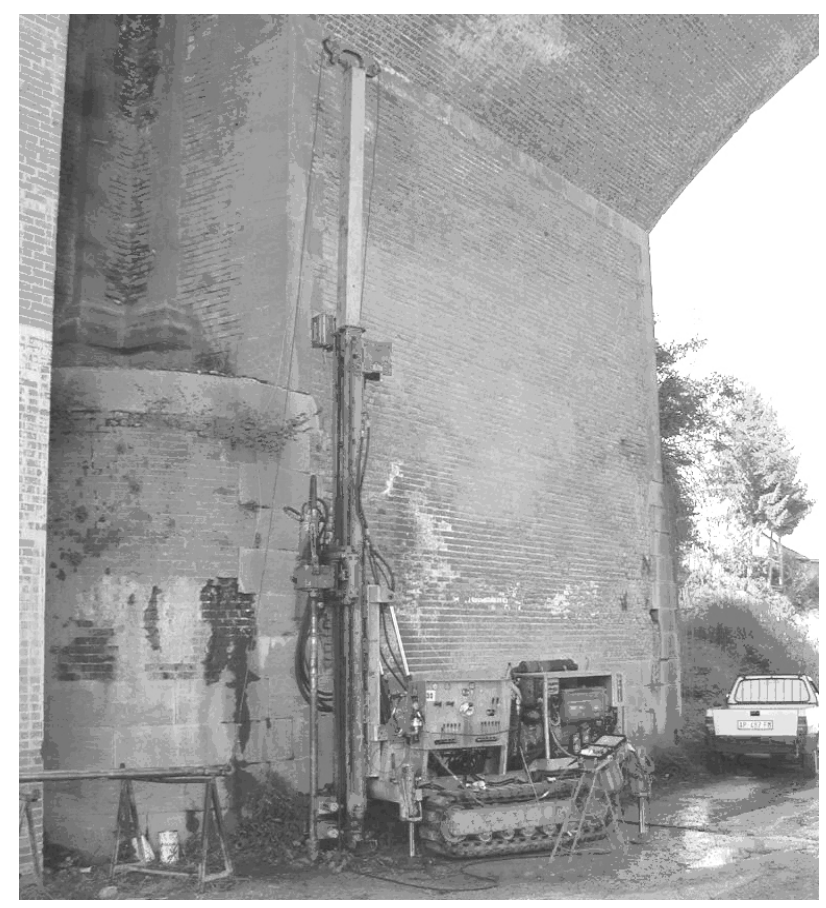

Fig. 3. Drilling equipment used for the core destruction monitoring drilling on the shoulder of the bridge over the Gesso Stream at Cuneo

Depth: $-15.80 \mathrm{~m}$ from ground level

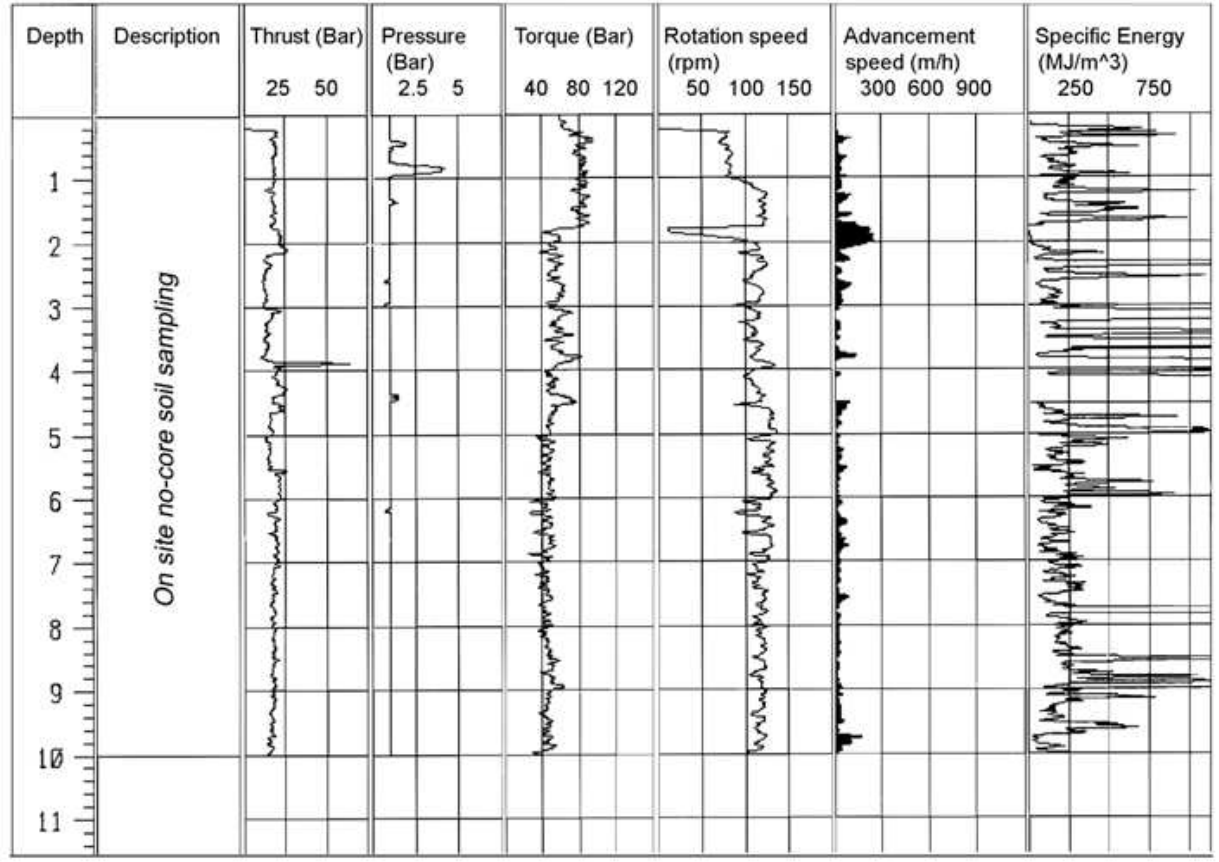

Fig. 4. Calibration diagraphy carried out close to the abutment of the bridge over the Gesso Stream (N.R.22 site, Cuneo) 


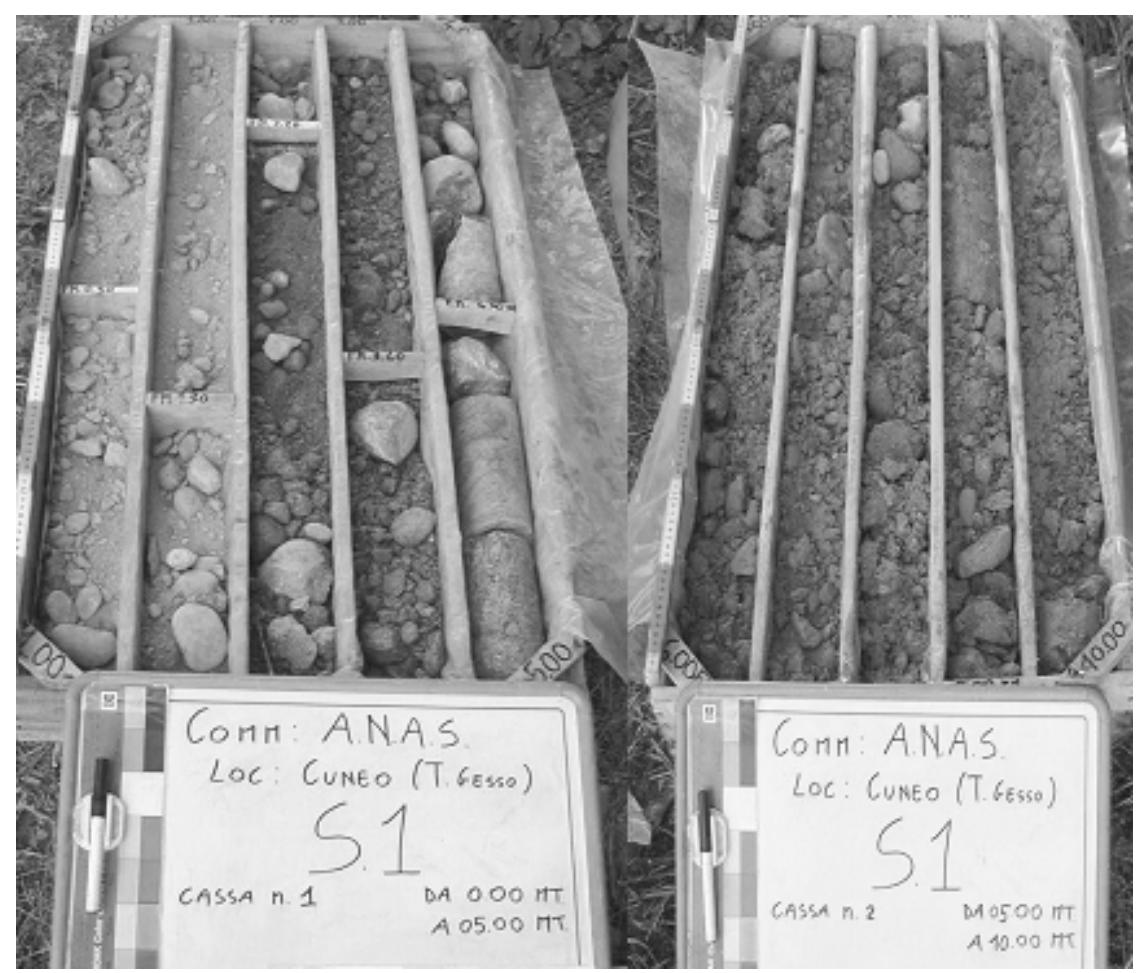

Fig. 5. Example of samples taken, by means of core drilling, along a length of $10 \mathrm{~m}$ close to the abutment of the bridge over the Gesso Stream (N.R. 22 site, Cuneo)

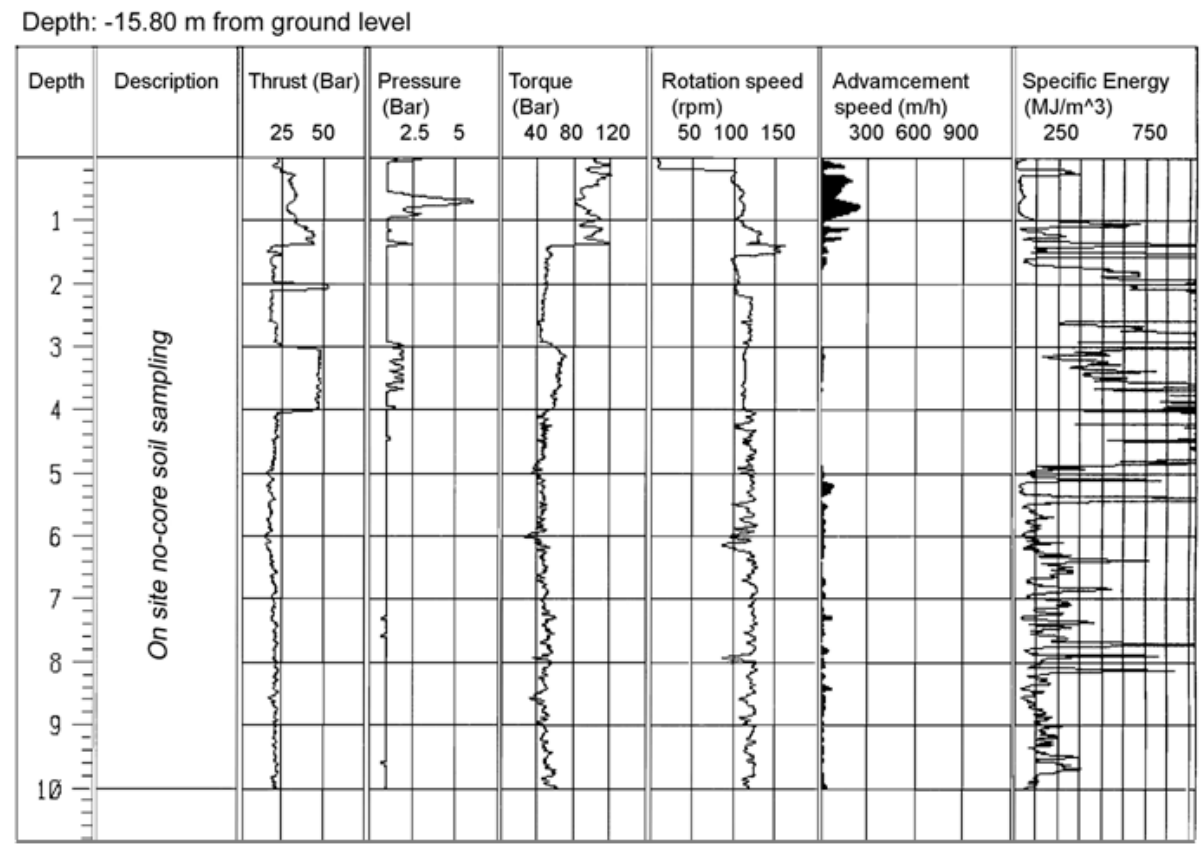

Fig. 6. Diagraphy carried out close to the abutment of the bridge over the Gesso Stream on the upper side (N.R. 22 site, Cuneo) 


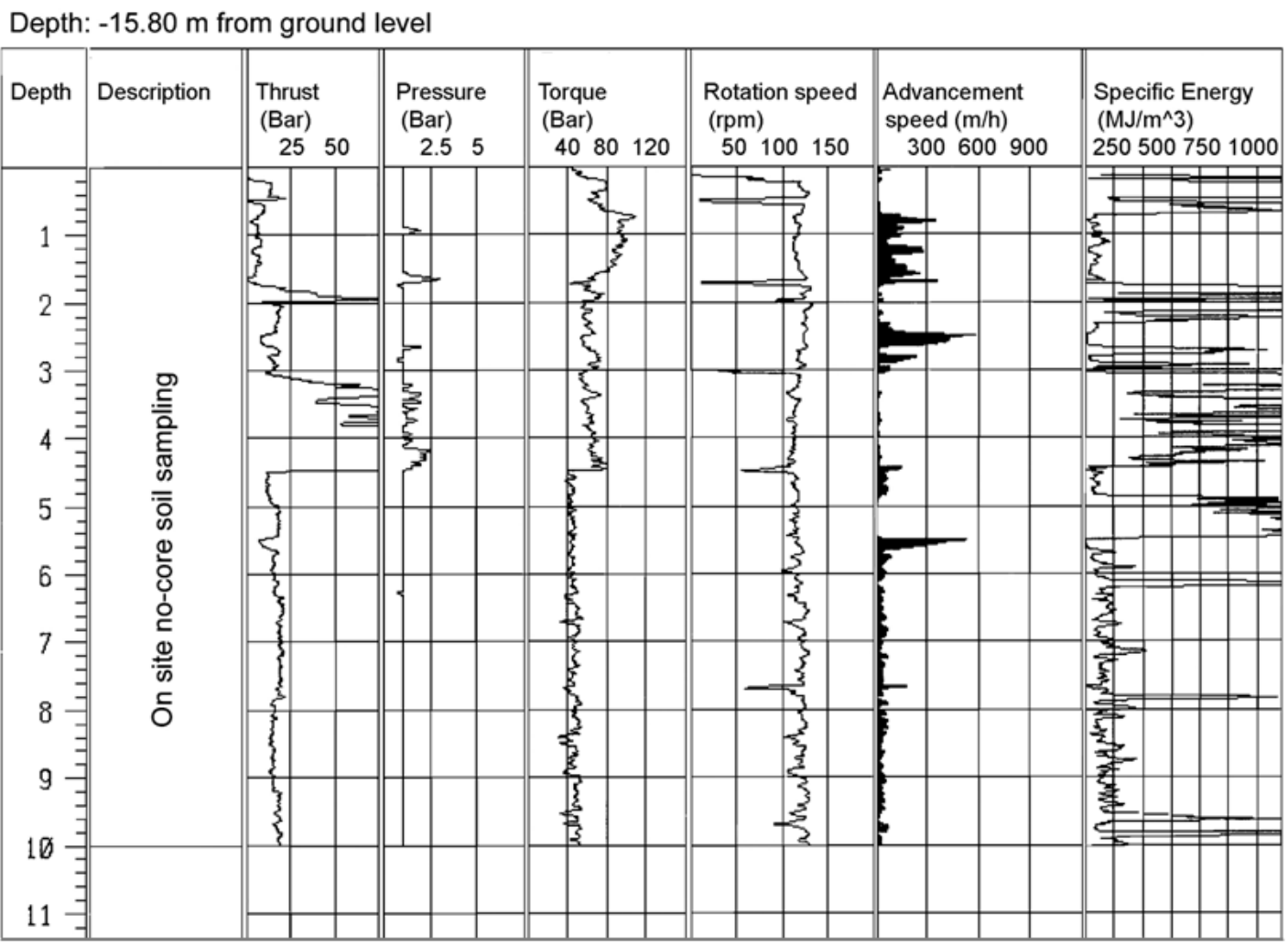

Fig. 7. Diagraphy obtained close to the abutment of the bridge over the Gesso Stream (N.R.22 site, Cuneo): two sharp reductions in the specific energy can be observed at depths of 4.5 and $5.5 \mathrm{~m}$

A sharp reduction in the tool thrust and a slight reduction in the rotation torque are also visible at $4.5 \mathrm{~m}$. At $5.5 \mathrm{~m}$, only a further localised decrease in the tool thrust can be observed, together with a relevant increase in the advancement speed.

The calibration diagraphy highlights constant mean specific energy values (about $125-150 \mathrm{MJ} / \mathrm{m}^{3}$ ) for greater depths than $4.5 \mathrm{~m}$ (Fig. 4).

It was also possible to observe very low specific energy values on the lower side of the bridge abutment, in the Cuneo direction, at a depth of $5.5 \mathrm{~m}$. These values are below the mean specific energy values obtained at a certain distance from the abutment foundations in the same type of soil. The presence of a certain undermining can therefore be deduced at the foot of the foundations on the lower side which also exists on the upper side, but to a lesser extent.

\subsection{Bridge over the River Po, National Road 211, Pieve Po, Italy}

Six diagraphies of different lengths, varying from 10 to $18 \mathrm{~m}$, were realised on the bridge over the Po at Pieve
Po, starting from the river bed. The first, $\mathrm{P} 1,10 \mathrm{~m}$ long, is the only one that directly intersects the bridge foundations. A substantial reduction in specific energy can be seen for P1 (Fig. 8) with very low values, below $40-50 \mathrm{MJ} / \mathrm{m}^{3}$, starting from the foundation-soil transition point (5.2 $\mathrm{m}$ in depth).

The other drilling parameters did not result to be anomalous during the crossing of the foundation ground. The specific drilling energy also constantly remains low for the entire section that involves the foundation ground. The other five diagraphies carried out directly on the river bed confirm that the specific drilling energy of the ground is very low in this site.

Finally, a remarkable reduction in the specific energy can be observed at the transition point between the foundation and the ground. The calibration surveys highlighted that it is the mechanical properties of the ground that cause the low specific energy values that were recorded in the P1 diagraphy. The poor mechanical characteristics of the ground on which the pile foundations are placed are confirmed. 


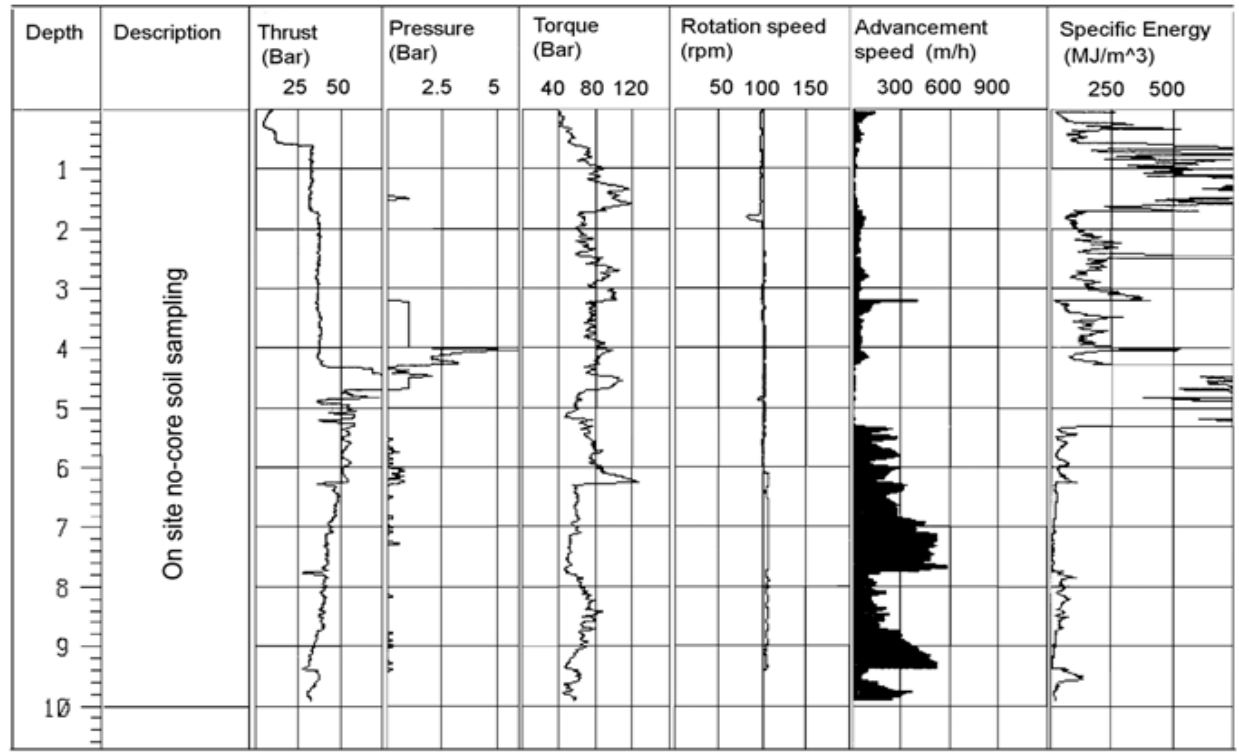

Fig. 8. Diagraphy obtained close to the abutment of the bridge over the Po river at Pieve: low specific energy values can be observed in the foundation soil, but without significant anomalies of other drilling parameters

\section{CONCLUSION}

Continuous Automatic Diagraphy (DAC) is an instrument that can be used to analyse the mechanical characteristics of soils and the degree of stress to which these soils are subject in situ. It consists in the continuous measuring of some important parameters, during drilling, that can lead to the evaluation of the specific energy excavation energy.

In this study, after having presented the method and the theoretical assumptions on which it is based, two application examples have been given in which DAC has proved to be particularly suitable to investigate the soils in great detail.

In the first case, the use of DAC has made it possible to confirm the cementation degree and geotechnical parameters of the Turin subsoil. In the second case, it has been possible to evaluate the conditions of the soil under the pile foundations of bridges on national roads, under the responsibility of ANAS.

\section{REFERENCES}

Barla, G. and L. Vai, 1999. Indagini geotecniche per la caratterizzazione del sottosuolo di Torino lungo il tracciato del Passante Ferroviario. Proceedings of the 20th Congresso Nazionale di Geotecnica, (CNG' 99), Parma, Italy, pp: 335-342.
Bellopede, R., F. Brusco, P. Oreste and M. Pepino, 2011. Main aspects of tunnel muck recycling. Am. J. Environ. Sci., 7: 338-347. DOI: 10.3844/ajessp.2011.338.347

Cardu, M. and P. Oreste, 2011. Tunnelling in urban areas by EPB machines: technical evaluation of the system. Earth Sci. Res. J., 15: 3-9.

Cardu, M., P. Oreste and T. Cicala, 2009. Analysis of the tunnel boring machine advancement on the bolognaflorence railway link. Am. J. Eng. Applied Sci., 2: 416-420. DOI: 10.3844/ajeassp.2009.416.420

Oggeri, C. and P. Oreste, 2012. Tunnel static behavior assessed by a probabilistic approach to the backanalysis. Am. J. Applied Sci., 9: 1137-1144. DOI: 10.3844/ajassp.2012.1137.1144

Oreste, P., 2005. Back-analysis techniques for the improvement of the understanding of rock in underground constructions. Tunnell. Underground Space Technol., 20: 7-21. DOI: 10.1016/j.tust.2004.04.002

De Rienzo F.D. and P. Oreste, 2011. Analyses of the Distribution and Nature of the Natural Cementation of Quaternary Sediments: The Case of the Turin Subsoil (Italy). Geotechn. Geol. Eng., 29: 319-328. DOI: $10.1007 /$ s10706-010-9378-5 
Marilena Cardu et al. / American Journal of Applied Sciences 10 (7): 654-663, 2013

De Rienzo F.D., P. Oreste and S. Pelizza, 2009. 3D GIS supporting underground urbanisation in the City of Turin (Italy). Geotechn. Geol. Eng., 27: 539-547. DOI: $10.1007 / \mathrm{s} 10706-009-9255-2$

De Rienzo, F.D., P. Oreste and S. Pelizza, 2008. Subsurface geological-geotechnical modelling to sustain underground civil planning. Eng. Geol., 96: 187-204. DOI: 10.1016/j.enggeo.2007.11.002
Teale, R., 1965. The concept of specific energy in rock drilling. Int. J. Rock Mech. Min. Sci. Geomech. Abstracts, 2: 57-73. DOI: 10.1016/01489062(65)90022-7 